\title{
Hydrochlorothiazide use and the risk of skin cancer in patients with hypertensive disorder: a nationwide retrospective cohort study from Korea
}

\author{
Eunjung Park ${ }^{1}$, Young Lee ${ }^{2}$, and Mihn-Sook Jue ${ }^{1}$
}

${ }^{1}$ Department of Dermatology, ${ }^{2}$ Veterans Medical Research Institute, Veterans Health Service Medical Center, Seoul, Korea

Received: July 1, 2019

Revised : July 26, 2019

Accepted: September 9, 2019

\section{Correspondence to}

Mihn-Sook Jue, M.D.

Department of Dermatology, Veterans Health Service Medical Center, 53 Jinhwangdo-ro 61gil, Gangdong-gu, Seoul 05368, Korea

Tel: $+82-2-2225-1388$

Fax: +82-2-2225-4374

E-mail: zooooz@hanmail.net https://orcid.org/0000-0002$8253-6188$
Background/Aims: Recent studies have shown a cumulative dose-dependent association between the use of hydrochlorothiazide (HCTZ) and skin cancer, including melanoma and non-melanoma skin cancer (NMSC) in Western Europe. However, whether this pattern is present in East Asia countries is unknown. The aim of this study was to examine the association between HCTZ use and the risk of skin cancer among a cohort of hypertensive patients in South Korea.

Methods: This was a retrospective, population-based cohort study using the database from the Health Insurance Review and Assessment Service between January 1, 2007 and June 30, 2017 in South Korea. We identified patients diagnosed with melanoma and NMSC in the cohorts of essential hypertensive patients who were treated with HCTZ or antihypertensive agents other than HCTZ. Using Cox proportional hazards regression models, the hazard ratios (HR) for skin cancer associated with HCTZ users were calculated.

Results: The risk of melanoma was significantly lower in HCTZ-users compared with non-HCTZ users (HR, 0.85; 95\% confidence interval [CI], 0.75 to $0.97 ; p=$ $0.016)$, and the risk of NMSC was lower in the HCTZ users but no statistically significant association was seen (HR, 0.96; $95 \% \mathrm{CI}$, 0.91 to 1.02; $p=0.236$ ). High cumulative doses $(\geq 50,000 \mathrm{mg}$ ) of HCTZ were associated with decreased risk of both NMSC (HR, 0.20; 95\% CI, o.10 to 0.38; $p<0.001)$ and melanoma (HR, 0.18; 95\% CI, 0.04 to $0.70 ; p=0.001)$, respectively.

Conclusions: High cumulative use of HCTZ may have a chemopreventive effect against the development of melanoma and NMSC with clear cumulative dose-response and duration-response relationships in South Korea.

Keywords: Hydrochlorothiazide; Non-melanoma skin cancer; Basal cell carcinoma; Squamous cell carcinoma; Melanoma

\section{INTRODUCTION}

Skin cancer is among the most common cancers with a rapidly increasing incidence worldwide [1-7]. Ultraviolet (UV) exposure is an established risk factor for skin cancer. The incidence rate of skin cancer highly depends on skin phenotype and geographic variations, which determine the amount of UV reaching the papillary dermis and is much lower in Asians compared to Caucasians [35,8-14]. Therefore, several factors, including ethnic and geographic variation, must be considered when interpreting data associated with skin cancer. 
Hydrochlorothiazide (HCTZ) is the one of the most commonly prescribed diuretic and antihypertensive agents and the first-line treatment in hypertensive disorder [15]. HCTZ exhibits known photosensitizing properties and recent studies reported that the use of HCTZ was associated with an increased risk of non-melanoma skin cancer (NMSC; including squamous cell carcinoma [SCC] and basal cell carcinoma [BCC]), melanoma, Merkel cell carcinoma, and malignant adnexal skin tumors [16-20]. In November 2018, the Medicines and Healthcare Products Regulatory Agency in the UK informed that HCTZ is associated with the risk of NMSC, particularly in long-term use. However, some studies have questioned this correlation and whether HCTZ increases the risk of skin cancer has been controversial [21-23]. In addition, no studies have examined HCTZ use and the risk of skin cancer in an Asian population. The inconsistent results and limited data in an Asian population inspired us to conduct a nationwide study on the association between HCTZ use and the risk of skin cancer in a South Korean population.

\section{METHODS}

\section{Study population and data collection}

This study is a population-based retrospective cohort study that used claims data of the Health Insurance Review and Assessment Service (HIRA) using the Korean Classification of Disease 8th revision (KCD-8) codes, which are similar to the 1oth revision of International Classification of Diseases (ICD-10) codes, from January 1, 2007 through June 30, 2017. In South Korea, approximately $98 \%$ of the Korean population is eligible to receive healthcare coverage under the National Health Insurance Service (NHIS), and the HIRA is the repository for NHIS data [24]. HIRA provides national records of the number of hospital visits, prescription drugs, and diagnosis of diseases in all covered inpatients and outpatients. Cancer diagnosis can be registered only after the diagnosis is confirmed by pathologic examination. Therefore, claims data from HIRA, especially cancer diagnosis, are considered reliable. Because of the homogeneity of the study population, data on race/ethnicity have not been collected. This study was approved by the Institutional Review Board at Veterans Health Service medical center, Seoul, South Korea (IRB number: 201803-025). The IRB approved a waiver of written informed consent for retrospective deidentified patient data. The stepwise approach for patient selection is summarized in Fig. 1. We generated a cohort of hypertensive patients ( $n=3,949,082)$ satisfying all of the following: (1) patients with a first diagnosis of essential (primary) hypertension (KCD-8 or ICD-10 code for I10) between January 1 , 2009 and December 31, 2016; (2) patients who received at least three prescriptions for any antihypertensive drug after diagnosis of I10; and (3) patients who were over 18 years old at the time of diagnosis of hypertension. We excluded patients who were diagnosed in 2007 to 2008 , prior to the registry date, with the following:(1) skin cancers (C43, C44, Do3, Do4); (2) other malignant neoplasms (Co1 to $\mathrm{C}_{26} 6, \mathrm{C}_{3} 0$ to $\mathrm{C}_{34}, \mathrm{C}_{37}$ to $\mathrm{C}_{41}, \mathrm{C}_{45}$ to $\mathrm{C}_{5} 8$, $\mathrm{C}_{60}$ to C86, C88, C9o to C97); (3) essential (primary) hypertension (I10); and (4) human immunodeficiency virus (B2O to B24). We also excluded patients who underwent the following between January 1, 2007 and June 30, 2017: (1) organ transplantation (T86, Z94); (2) $\geq 6$ months administration of immunosuppressant agents (cyclosporine A, azathioprine, mycophenolate mofetil); and (3) had been diagnosed with skin cancer prior to the diagnosis of hypertension. NMSC was defined as ICD-10 code of "C44" (Other malignant neoplasm of skin) and "Do4" (Carcinoma in situ of skin), and melanoma was defined as "C43" (Malignant melanoma of skin), and "Do3" (Melanoma in situ). The hypertensive patient cohort was divided into those who were treated with HCTZ ("HCTZ-users") and those treated with antihypertensive agents other than HCTZ ("non-HCTZ-users"). In both groups, we obtained baseline demographic information, including patient age at the time of cohort registry, sex, comorbidities using Charlson comorbidity index (CCI) scores, concurrent use of photosensitizing drugs (tetracyclines, hydroxychloroquine, oral retinoids, antibiotics, photosensitizing antihypertensive drugs, non-steroidal anti-inflammatory drugs [NSAIDs], other diuretics), and other drugs potentially affecting skin cancer (aspirin, systemic corticosteroids, statins).

\section{Assessment of exposure}

Follow-up was initiated on the first day of the administration of antihypertensive agents and ended on June 30, 2017 or at the time of first diagnosis with skin cancer. 


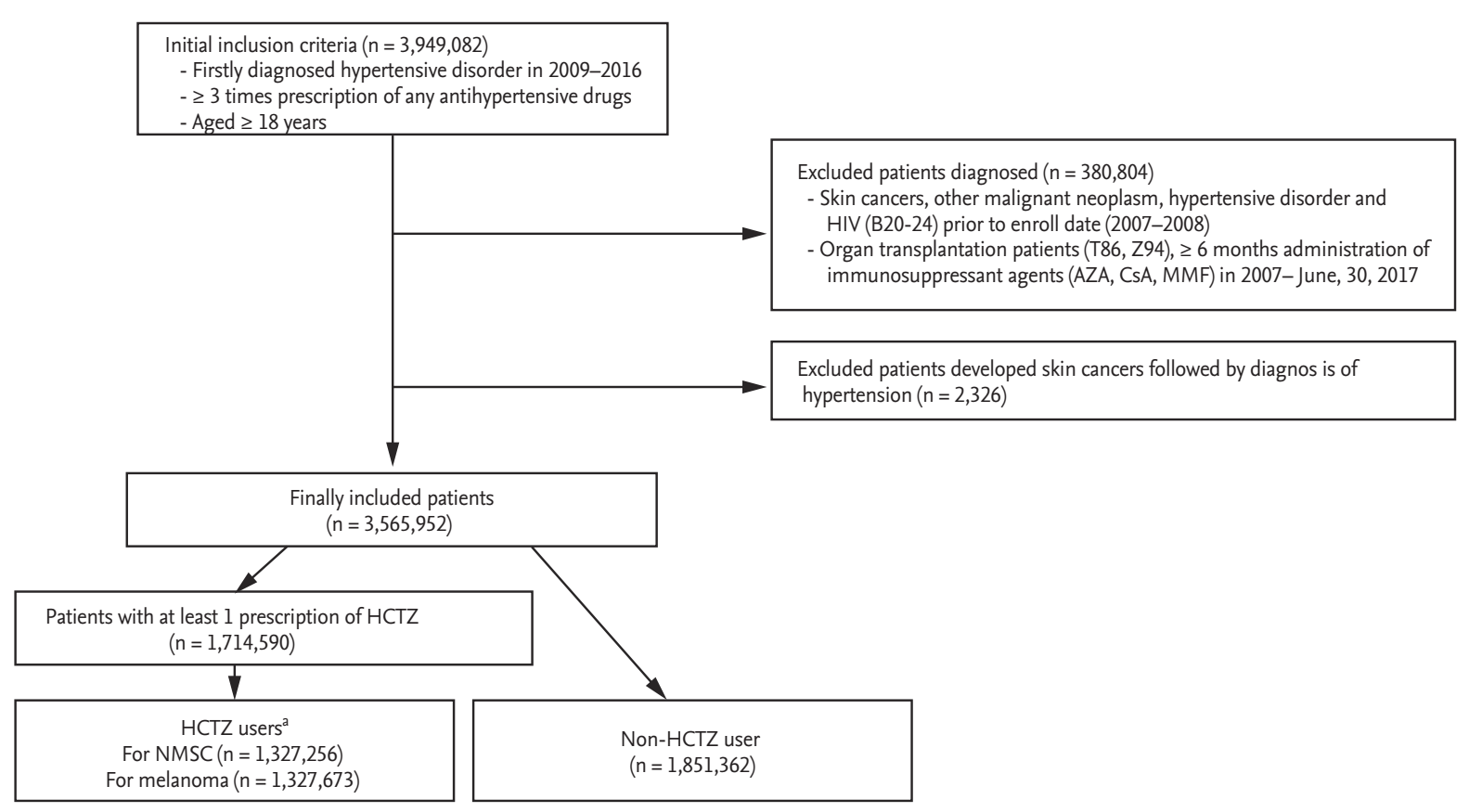

Figure 1. The stepwise approach for patient selection. HIV, human immunodeficiency virus; AZA, azathioprine; CsA, cyclosporine A; MMF, mycophenolate mofetil; HCTZ, hydrochlorothiazide; NMSC, non-melanoma skin cancer. ${ }^{2}$ Having at least three prescriptions of HCTZ prior to the first diagnosis of skin cancer (NMSC, melanoma) or on June, 30, 2017.

We defined the date of the end of follow-up as the index date. "HCTZ-users" were defined as patients having at least three prescriptions for HCTZ and "non-HCTZ-users" were defined as patients never prescribed for HCTZ during the follow-up period. We also investigated cumulative doses and duration of HCTZ. We also divided HCTZ users into "low users" as < 50,000 mg and "high users" as $\geq 50,000 \mathrm{mg}$. Cumulative doses of HCTZ were also categorized into quartiles as follows (NMSC/melanoma): Quartile 1 (3.125 to 2,699.99 mg/3.125 to 2,699.99 mg), Quartile 2 (2,700.0 to 7,268.74 mg/2,700.0 to 7,274.99 mg), Quartile $3(7,268.75$ to $16,487.49 \mathrm{mg} / 7,275.00$ to $16,499.99$ $\mathrm{mg})$, and Quartile 4 (16,487.50 to 8,332,212.5 mg/16,500.00 to $8,332,212.5 \mathrm{mg}$ ). Exposure to other drugs was also defined as at least 3 prescriptions for each drug.

\section{Covariates}

We included covariates as follows: (1) age; (2) sex; (3) CCI scores (o, low; 1 to 2, medium; $\geq 3$, high); (4) use of photosensitizing drugs included as follows: (1) tetracyclines (doxycycline, tetracycline), (2) antimalarials (hydroxychloroquine), (3) oral retinoids (acitretin, isotretinoin), (4) antibiotics (ciprofloxacin, levofloxacin, trimethoprim/sulfamethoxazole), (5) NSAIDs (ibuprofen, naproxen, piroxicam, diclofenac, celecoxib), (6) other diuretics (amiloride, azosemide, furosemide, torasemide, xipamide, chlorthalidone, indapamide, spironolactone), (7) photosensitizing antihypertensive drugs (angiotensin converting enzyme inhibitors [enalapril, ramipril, temocapril], calcium channel blockers [amlodipine, lercanidipine, nifedipine, diltiazem, verapamil, gallopamil], angiotensin II receptor blockers [valsartan, losartan, olmesartan, telmisartan, candesartan, fimasartan], beta-blockers [carvedilol, atenolol]), and (8) hypoglycemics (glimepiride, glibenclamide, gliclazide); and (5) the use of other drugs potentially affecting skin cancer as follows: (1) antiplatelet agent (aspirin), (2) systemic glucocorticoid (hydrocortisone, methylprednisolone, triamcinolone), and (3) statins (simvastatin, lovastatin, atorvastatin).

\section{Statistical analysis}

Continuous variables were expressed as means \pm standard deviations (SD). Categorical variables were expressed as frequencies or percentages. The Student $t$ test for continuous variables and chi-square test for categorical variables were used to compare characteristics 
of study subjects. The incidence rates were presented as events per 100,000 patient-years (PY) with exact Poisson confidence intervals of $95 \%$. Associations of exposure to HCTZ and skin cancer were summarized with hazard ratios (HRs) and 95\% confidence intervals, estimated with Cox proportional model adjusted age, sex, and CCI score. Fully adjusted model additionally adjusted for (1) concurrent use of photosensitizing drugs (tetracyclines, hydroxychloroquine, oral retinoids, antibiotics, photosensitizing antihypertensive drugs, NSAIDs, other diuretics); and (2) concurrent use of drugs potentially affecting skin cancer (aspirin, systemic corticosteroids, statins). To evaluate effects of the cumulative duration and dose-response relationship between HCTZ and skin cancer, the HRs were individually calculated by the lowest dose (<10,000 mg and Quartile 1) and the shortest duration (<1 year) groups of HCTZ as references. All statistical analyses in this study were performed using statistical program $\mathrm{R}$ version 3.4.1. (The R Foundation for Statistical Computing, Vienna, Austria) and SAS version 9.3 (SAS Institute, Cary, NC, USA). A p < 0.05 was considered to be statistically significant.

\section{RESULTS}

\section{Relation of exposure to HCTZ and the risk of NMSC} A total of 1,327,256 HCTZ-users and 1,851,362 non-HCTZusers were included in this study. The mean age \pm SD of HCTZ-users and non-HCTZ-users were $55.8 \pm 12.7$ and $55.1 \pm 12.9$ years, respectively. The 50 to 64 year old group was predominant in both groups (41.6\% in HCTZ-users and $43.2 \%$ in non-HCTZ-users). HCTZ-users had a statistically higher proportion of females compared with the non-HCTZ users $(p<0.001)$. Both groups had a tendency to have more comorbidities with high CCI scores ( $\geq 3)$, corresponding to $64.4 \%$ of HCTZ-users and $59.7 \%$ of non-HCTZ-users. Concurrent use of photosensitizing drugs and other drugs potentially affecting skin cancer is described in detail in Table 1. As more than 80 photosensitizing drugs were administered simultaneously in the hypertensive patient cohorts, only a few drugs are listed in Table 1 in order of frequency.

NMSC developed in 2,115 and 2,811 HCTZ-users and non-HCTZ users, respectively. The incidence rate of NMSC was 28.04 per 100,000 PY among HCTZ-users and 33.64 per 100,000 PY among non-HCTZ-users, yielding an age-, sex-, and comorbidities-adjusted HR of 0.72 (95\% CI, 0.68 to $0.77 ; p<0.001$ ) and fully-adjusted HR of 0.96 (95\% CI, 0.91 to 1.02; $p=0.236$ ). High HCTZ-users $(\geq$ $50,000 \mathrm{mg}$ of cumulative doses) had fully-adjusted HR of 0.22 (95\% CI, o.11 to 0.42) in NMSC compared with nonHCTZ-users (Table 2). Clear cumulative dose-response and duration-response relationships were observed in increasing exposure of HCTZ in NMSC ( $p$ trend $<0.001$ ) (Table 3 and Fig. 2).

\section{Relation of exposure to HCTZ and the risk of melanoma}

A total of 1,327,673 HCTZ-users and 1,851,362 non-HCTZ users was included in this study. Other characteristics of study subjects are described in detail in Table 1. Melanoma developed in 460 and 706 HCTZ-users and nonHCTZ-users, respectively. Age-, sex-, and comorbidities-adjusted HR was 0.63 (95\% CI, 0.56 to $0.71 ; p<0.001$ ), and fully-adjusted HR was 0.85 (95\% CI, 0.75 to $0.97 ; p$ $=0.016)$. High HCTZ users $(\geq 50,000 \mathrm{mg}$ of cumulative doses) had HRs of 0.20 (95\% CI, 0.05 to 0.79 ; $p=0.022$ ) in melanoma compared with non-HCTZ users (Table 2). Clear cumulative dose-response and duration-response relationships were observed in increasing exposure of HCTZ in melanoma ( $p$ trend < 0.001) (Table 3 and Fig. 2).

\section{DISCUSSION}

In this large, population-based, retrospective study, we found that the risk of melanoma was significantly reduced in HCTZ-users compared with non-HCTZ-users (HR, 0.85; 95\% CI, 0.75 to $0.97 ; p=0.016$ ) and the risk of NMSC was slightly reduced, but no significance was observed (HR, 0.96; 95\% CI, 0.91 to 1.02; $p=0.236$ ). High cumulative doses $(\geq 50,000 \mathrm{mg}$ and cumulative doses of $\geq$ quartiles 3 ) of HCTZ were significantly associated with decreased risk for both melanoma and NMSC. We also found clear cumulative dose-response and duration-response relationships between HCTZ and both NMSC and melanoma ( $p$ trend $<0.001$ ). This study showed a decreased risk of skin cancer with the cumulative dose of HCTZ. Notably, our results are different than previous studies that reported an increased risk or no associated risk of skin cancer with the use of HCTZ. 
Table 1. Characteristics of study subjects according to types of skin cancer

\begin{tabular}{|c|c|c|c|c|c|c|}
\hline \multirow[b]{2}{*}{ Characteristic } & \multicolumn{3}{|c|}{ NMSC } & \multicolumn{3}{|c|}{ Melanoma } \\
\hline & $\begin{array}{l}\text { HCTZ users } \\
(\mathrm{n}=1,327,256)\end{array}$ & $\begin{array}{c}\text { Non-HCTZ } \\
\text { users }(n=1,851,362)\end{array}$ & $p$ value & $\begin{array}{l}\text { HCTZ users } \\
(\mathrm{n}=1,327,673)\end{array}$ & $\begin{array}{l}\text { Non-HCTZ users } \\
\quad(n=1,851,362)\end{array}$ & $p$ value \\
\hline Age, yr & $55.8 \pm 12.7$ & $55.1 \pm 12.9$ & $<0.001^{\mathrm{a}}$ & $55.8 \pm 12.7$ & $55.1 \pm 12.9$ & $<0.001^{\mathrm{a}}$ \\
\hline \multicolumn{7}{|l|}{ Age_groups, yr } \\
\hline $18-34$ & $44,664(3 \cdot 4)$ & $85,918(4 \cdot 6)$ & & $44,664(3 \cdot 4)$ & $85,918(4 \cdot 6)$ & \\
\hline $35-49$ & $393,682(29 \cdot 7)$ & $539,033(29.1)$ & & $393,707(29.7)$ & $539,033(29.1)$ & \\
\hline $50-64$ & $552,018(41.6)$ & $800,226(43.2)$ & & $552,092(41.6)$ & $800,226(43.2)$ & \\
\hline$\geq 65$ & $336,892(25 \cdot 4)$ & $426,185(23.0)$ & & $337,210(25 \cdot 4)$ & $426,185(23.0)$ & \\
\hline Sex & & & $<0.001^{\mathrm{a}}$ & & & $<0.001^{\mathrm{a}}$ \\
\hline Male & $693,107(52.2)$ & $1,089,555(58.9)$ & & $693,265(52.2)$ & $1,089,555(58.9)$ & \\
\hline Female & $634,149(47.8)$ & $761,807(41.1)$ & & $634,408(47.8)$ & $761,807(41.1)$ & \\
\hline \multicolumn{7}{|c|}{ Charlson comorbidity index score } \\
\hline o (low) & $70,990(5 \cdot 3)$ & $118,303(6.4)$ & & $70,991(5 \cdot 3)$ & $118,303(6.4)$ & \\
\hline 1-2 (medium) & $401,867(30.3)$ & $628,634(34.0)$ & & $401,866(30.3)$ & $628,634(34.0)$ & \\
\hline$\geq 3$ (high) & $854,399(64.4)$ & $1,104,425(59 \cdot 7)$ & & $854,816(64.4)$ & $1,104,425(59 \cdot 7)$ & \\
\hline \multicolumn{7}{|c|}{ Concurrent use of photosensitizing drugs ${ }^{b}$} \\
\hline Amlodipine & $763,125(57 \cdot 5)$ & $1,062,828(57 \cdot 4)$ & 0.116 & $763,508(57 \cdot 5)$ & $1,063,077(57.4)$ & 0.127 \\
\hline Losartan & $620,168(46.7)$ & $383,786(20.7)$ & $<0.001^{\mathrm{a}}$ & $620,399(46.7)$ & $383,869(20.7)$ & $<0.001^{\mathrm{a}}$ \\
\hline Valsartan & $417,282(31.4)$ & $389,835(21.1)$ & $<0.001^{\mathrm{a}}$ & $417,527(31.4)$ & $389,958(21.1)$ & $<0.001^{\mathrm{a}}$ \\
\hline Telmisartan & $284,014(21.4)$ & $281,247(15 \cdot 2)$ & $<0.001^{\mathrm{a}}$ & $284,144(21.4)$ & $281,305(15 \cdot 2)$ & $<0.001^{\mathrm{a}}$ \\
\hline Olmesartan & $262,594(19.8)$ & $220,217(11.9)$ & $<0.001^{\mathrm{a}}$ & $262,736(19.8)$ & $220,282(11.9)$ & $<0.001^{\mathrm{a}}$ \\
\hline Candesartan & $153,248(11.5)$ & $121,081(6.5)$ & $<0.001^{\mathrm{a}}$ & $153,317(11.5)$ & $121,119(6.5)$ & $<0.001^{\mathrm{a}}$ \\
\hline Glimepiride & $142,651(10.7)$ & $155,995(8.4)$ & $<0.001^{\mathrm{a}}$ & $142,729(10.8)$ & $156,042(8.4)$ & $<0.001^{\mathrm{a}}$ \\
\hline Carvedilol & $122,643(9.2)$ & $134,532(7 \cdot 3)$ & $<0.001^{\mathrm{a}}$ & $122,718(9.2)$ & $134,581(7 \cdot 3)$ & $<0.001^{\mathrm{a}}$ \\
\hline Levofloxacin & $121,231(9.1)$ & $121,145(6.5)$ & $<0.001^{\mathrm{a}}$ & $121,939(9.1)$ & $121,238(6.5)$ & $<0.001^{\mathrm{a}}$ \\
\hline Celecoxib & $119,071(9.0)$ & $108,138(5.8)$ & $<0.001^{\mathrm{a}}$ & $119,317(9.0)$ & $108,333(5 \cdot 9)$ & $<0.001^{\mathrm{a}}$ \\
\hline Ciprofloxacin & $106,527(8.0)$ & $106,308(5 \cdot 7)$ & $<0.001^{\mathrm{a}}$ & $106,656(8.0)$ & $106,401(5 \cdot 7)$ & $<0.001^{\mathrm{a}}$ \\
\hline \multicolumn{7}{|c|}{ Concurrent use of other drugs affecting skin cancer } \\
\hline Atorvastatin & $420,486(31.7)$ & $481,284(26.0)$ & $<0.001^{\mathrm{a}}$ & $420,739(31.7)$ & $481,455(26.0)$ & $<0.001^{\mathrm{a}}$ \\
\hline Aspirin & $392,984(29.6)$ & $433,731(23.4)$ & $<0.001^{\mathrm{a}}$ & $393,232(29.6)$ & $433,896(23.4)$ & $<0.001^{\mathrm{a}}$ \\
\hline Methylprednisolone & $377,704(28.5)$ & $404,495(21.8)$ & $<0.001^{\mathrm{a}}$ & $378,087(28.5)$ & $404,742(21.9)$ & $<0.001^{\mathrm{a}}$ \\
\hline Prednisolone & $350,951(26.4)$ & $346,590(18.7)$ & $<0.001^{\mathrm{a}}$ & $351,308(26.5)$ & $346,775(18.7)$ & $<0.001^{\mathrm{a}}$ \\
\hline Simvastatin & $83,777(6.3)$ & $67,847(3.7)$ & $<0.001^{\mathrm{a}}$ & $83,823(6.3)$ & $67,867(3.7)$ & $<0.001^{\mathrm{a}}$ \\
\hline
\end{tabular}

Values are presented as mean $\pm \mathrm{SD}$ or number (\%).

NMSC, non-melanoma skin cancer; HCTZ, hydrochlorothiazide.

${ }^{a} p<0.05$ for HCTZ-users versus non-HCTZ users.

${ }^{\mathrm{b}}$ Only some of the concurrently administered photosensitizing drugs are listed in order of frequency.

Antihypertensive drugs are usually continuously administered for the treatment of chronic conditions [15]. Many of these drugs are classified as photosensitizers, which can trigger phototoxic or photoallergic reactions
[21-23,25-29]. Several concerns have been raised regarding the association of these drugs with increased skin cancer risk. Recently, based on two recent pharmacoepidemiological case-control studies from Denmark, the 


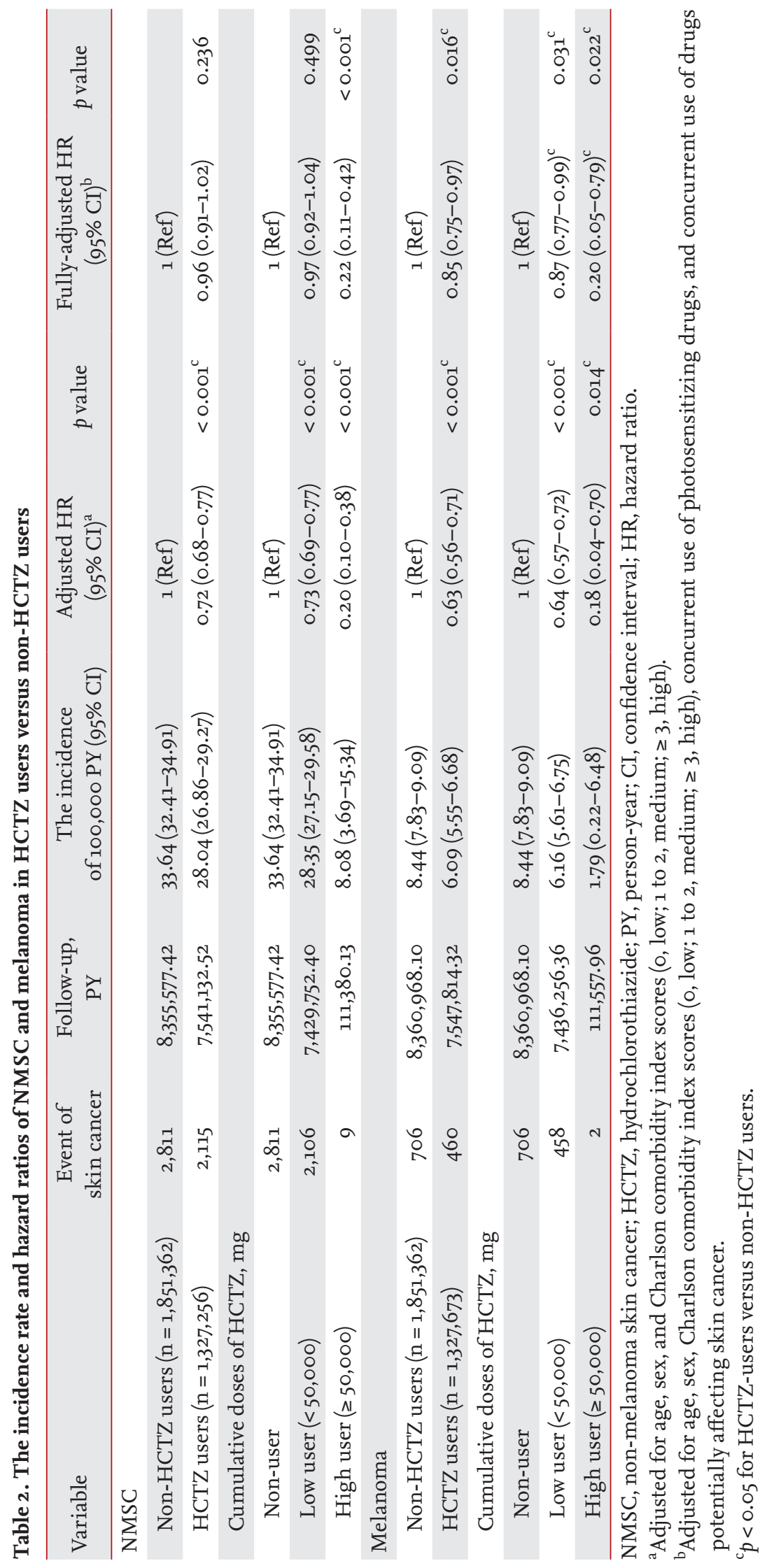




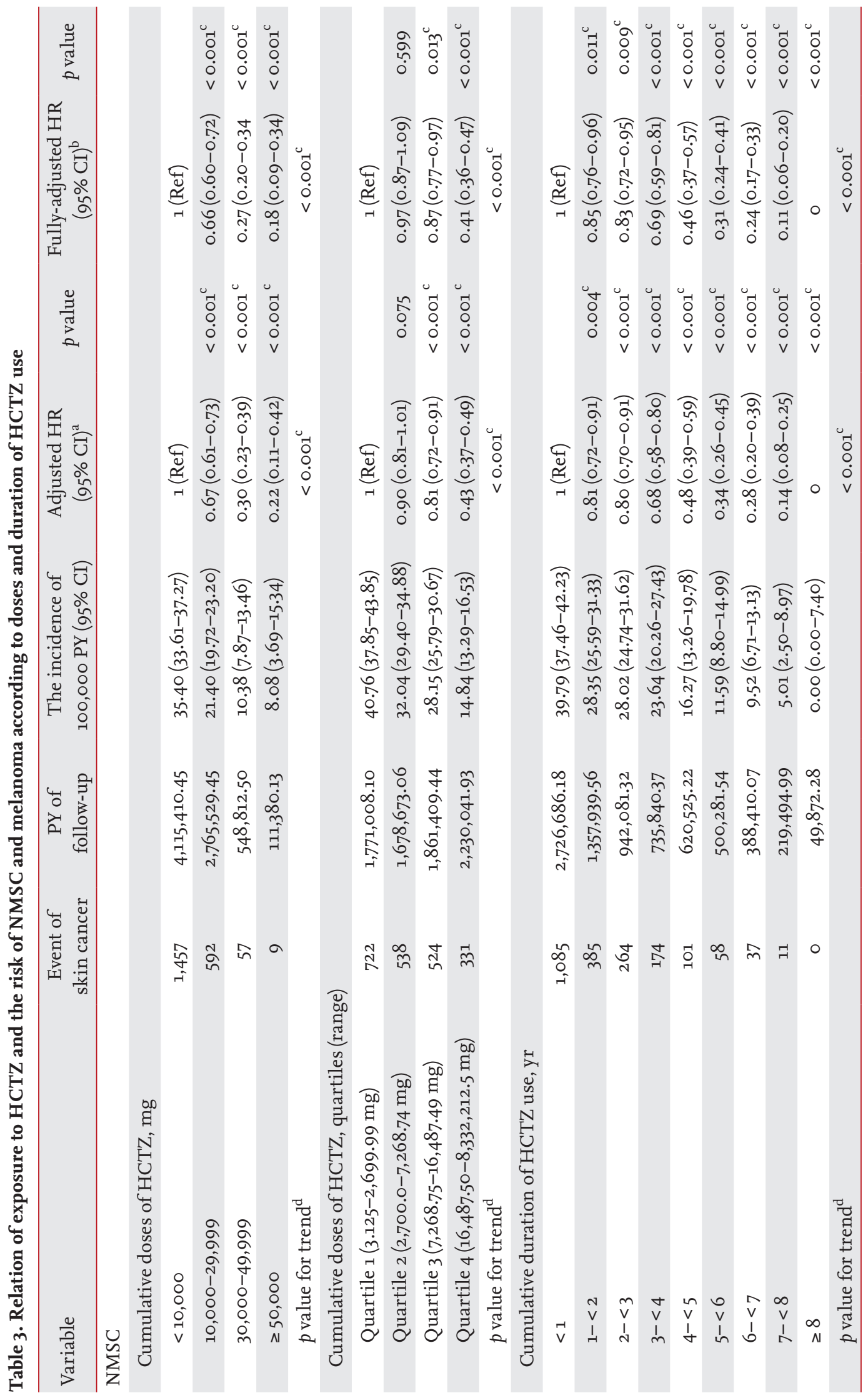




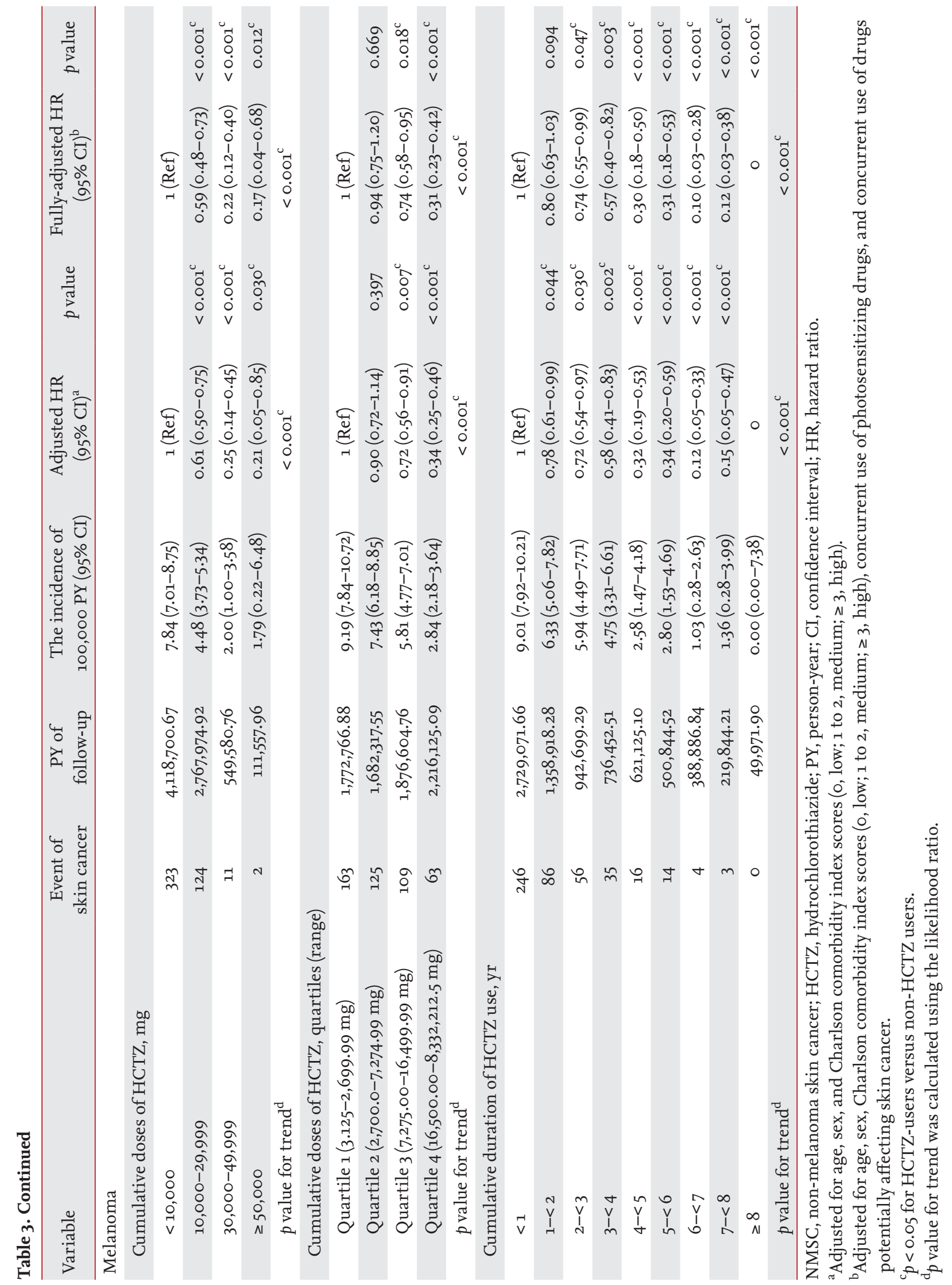



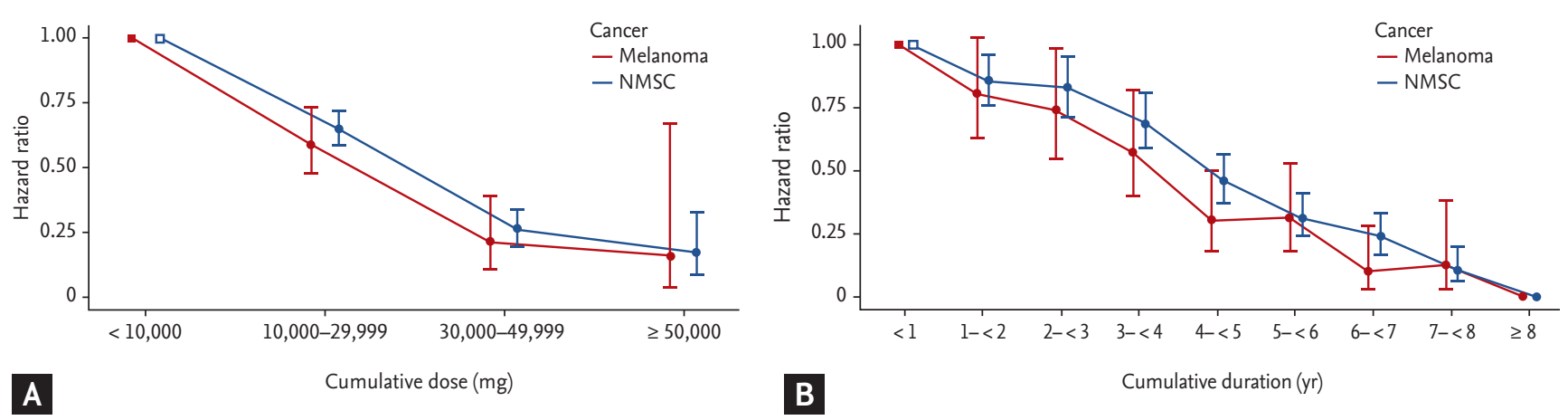

Figure 2. (A) Dose-response and (B) duration-response patterns of hydrochlorothiazide (HCTZ) and the risk of non-melanoma skin cancer (NMSC) and melanoma. Error bars represent $95 \%$ confidence intervals.

European Medicines Agency warned that long-term use of HCTZ may increase the risk of NMSC and recommended regular checks for any suspicious skin lesions or moles [30]. In these two Danish studies, Pedersen et al. [19] and Pottegard et al. [18] reported that cumulative doses of HCTZ were associated with increased risk of NMSC and SCC lip cancer, respectively. In contrast, a meta-analysis study by Gandini et al. [21] showed no significant increase in the risk of skin cancer in thiazide users, and a Danish cohort study by Kaae et al. [22] found no association between long-term daily use of bendroflumethiazide and increased risk of skin cancer. However, the two Danish studies were not statistically adjusted for concurrent use of other antihypertensive drugs that may have photosensitizing properties; the studies also have the possibility of selection bias and diagnostic bias from challenges associated with case-control studies [31]. The meta-analyses might have underestimated the association between drug use and skin cancer with differences in the definition of exposure to the drugs and the diversity of study designs among multiple studies. In addition, these studies focused on a wide range of hypertensive drugs rather than focusing on HCTZ alone; thus, they do not accurately represent the association between skin cancer risk and use of HCTZ. As these epidemiological studies offer inconsistent results of the association between diuretics including HCTZ and the risk of skin cancer with some limitations, whether HCTZ use increases the risk of skin cancer remains controversial.

The strengths of the current study include the population-based design and large sample size based on nationwide registries with accurate information, includ- ing prescription data, medical conditions, and skin or other cancer diagnoses, thus minimizing the possibility of selection and information bias. In the statistical analyses in this study, comorbidities and a number of concurrent medications including immunosuppressant agents (cyclosporine A, azathioprine, mycophenolate mofetil), photosensitizing drugs, and other drugs potentially affecting skin cancer were adjusted for potential confounders. In addition, by defining HCTZ-users as those with at least three prescriptions, the effects of drug compliance and prescription code errors are minimized. The possibility of diagnostic bias was also minimized by using cohorts of hypertensive patients. Based on these strengths, we propose that our study shows reliability and provides valuable results in clarifying the association of HCTZ use and skin cancer.

There may be several explanations for our findings that showed the decreased risk of skin cancer with HCTZ use. First, differences of race/ethnicity of the study population may explain the contradictory results with previous studies. Korea has a lower incidence of skin cancer and different baseline risk of skin cancer compared with Western countries, including geographic variation (latitude), skin phenotype, and lifestyle for sun exposure [3,4,6,7,10,14]. Most Koreans have a lifestyle that is less prone to UV exposure and a Fitzpatrick skin phenotype III (55.0\% to $78.9 \%)$ and IV (29.0\%), resulting in less sunburn potential than the Western population $[8,32]$. This reduced UV exposure may reduce the intensity of the photosensitizing properties of HCTZ, which are considered as the possible mechanism for the risk of skin cancer. Second, the anti-cancer activity of HCTZ may have counteracted or overwhelmed the potential 
carcinogenetic effects of photosensitivity of HCTZ. Although photosensitizing property of HCTZ is well known, little is known about the possible anti-cancer properties of HCTZ. HCTZ may exert antioxidative effects from direct inhibition of vascular NADPH oxidase activity and reduce matrix metalloproteinase 2 (MMP2) levels and activity [33-35]. MMPs play a role in tumor progression by enhancing tumor-induced angiogenesis and breakdown of extracellular matrix, resulting in the destruction of local tissue architecture and basement membranes to allow tumor invasion and metastasis in NMSC and melanoma [34,36]. O'Grady et al. [37] reported that increased expression of MMPs are related to the depth of lesion, inflammation, and microvessel density in NMSC and may be useful indicators of cutaneous cancer invasion and progression. Therefore, we postulate that the anti-cancer activities of HCTZ, through its antioxidative and MMP inhibitory effects, may have counteracted the photosensitizing effects and contributed to the overall decrease in the risk of skin cancer in HCTZ-users.

This study also has some limitations. First, the NMSC cases were not divided into SCC and BCC because of the heterogeneity of $\mathrm{C} 44$ (other malignant neoplasm of skin), so the association between the use of HCTZ and BCC and SCC could not be examined. Second, UV exposure have been reported to increase the risk of skin cancer also in Korean, but as our study was register-based, we did not have access to individual-level data on history of UV exposure and skin phenotype [38]. However, this study was conducted in a homogeneous study population with similar race/ethnicity, and thus we presume that UV exposure and skin phenotypes can be regarded as not markedly different between HCTZ-users and non-HCTZ-users. Lastly, due to the limited availability of mortality rate from HIRA database, death rate during the follow-up period could not be evaluated as a confounding factor in this study. This is the original study about the association with the use of HCTZ and the risk of skin cancers in Asian population and suggests a protective effect of HCTZ against skin cancer. As our study shows contrary findings to previous studies, further population- and ethnicity-based epidemiological studies of HCTZ will be needed to elucidate the association between HCTZ and the risk of skin cancer.

In conclusion, the use of HCTZ seems to have a che- mopreventive effect against NMSC and melanoma in a Korean population. High cumulative doses $(\geq 50,000$ $\mathrm{mg}$ ) of HCTZ may decrease the risk of both melanoma and NMSC in South Korea.

\section{KEY MESSAGE}

1. Hydrochlorothiazide has a photosensitizing property, and recent studies reported that hydrochlorothiazide was associated with an increased risk of skin cancer in Western countries.

2. In this study, cumulative use of hydrochlorothiazide was associated with decreased risk of skin cancer with clear cumulative dose-response and duration-response relationship.

3. Use of hydrochlorothiazide may have a chemopreventive effect against skin cancer in Korean.

\section{Conflict of interest}

No potential conflict of interest relevant to this article was reported.

\section{Acknowledgments}

This study is conducted jointly with the Big Data Department of the Health Insurance Review and Assessment Service (HIRA) in 2018.

\section{REFERENCES}

1. de Vries E, Trakatelli M, Kalabalikis D, et al. Known and potential new risk factors for skin cancer in European populations: a multicentre case-control study. Br J Dermatol 2012;167:1-13.

2. Han J, Colditz GA, Hunter DJ. Risk factors for skin cancers: a nested case-control study within the Nurses' Health Study. Int J Epidemiol 2006;35:1514-1521.

3. Elwood JM, Lee JA, Walter SD, Mo T, Green AE. Relationship of melanoma and other skin cancer mortality to latitude and ultraviolet radiation in the United States and Canada. Int J Epidemiol 1974;3:325-332.

4. Kricker A, Armstrong BK, English DR, Heenan PJ. Pigmentary and cutaneous risk factors for non-melanocytic skin cancer: a case-control study. Int J Cancer 1991;48:650- 
662.

5. Liu-Smith F, Farhat AM, Arce A, et al. Sex differences in the association of cutaneous melanoma incidence rates and geographic ultraviolet light exposure. J Am Acad Dermatol 2017;76:499-505.

6. Lomas A, Leonardi-Bee J, Bath-Hextall F. A systematic review of worldwide incidence of nonmelanoma skin cancer. Br J Dermatol 2012;166:1069-1080.

7. Oh CM, Cho H, Won YJ, et al. Nationwide trends in the incidence of melanoma and non-melanoma skin cancers from 1999 to 2014 in South Korea. Cancer Res Treat 2018;50:729-737.

8. Cho C, Ruan P, Lee E, Ha J. Comparison of skin color between two Asian populations: according to latitude and UV exposure. J Cosmet Dermatol 2015;14:22-26.

9. Crombie IK. Variation of melanoma incidence with latitude in North America and Europe. Br J Cancer 1979;40:774-781.

10. Gloster HM Jr, Neal K. Skin cancer in skin of color. J Am Acad Dermatol 2006;55:741-760.

11. Halder RM, Nootheti PK. Ethnic skin disorders overview. J Am Acad Dermatol 2003;48:S143-S148.

12. Kricker A, Armstrong BK, English DR, Heenan PJ. Does intermittent sun exposure cause basal cell carcinoma? A case-control study in Western Australia. Int J Cancer 1995;60:489-494.

13. Taylor SC. Skin of color: biology, structure, function, and implications for dermatologic disease. J Am Acad Dermatol 2002;46:S41-S62.

14. Wu XC, Eide MJ, King J, et al. Racial and ethnic variations in incidence and survival of cutaneous melanoma in the United States, 1999-2006. J Am Acad Dermatol 2011;65:S26-S37.

15. Whelton PK, Carey RM, Aronow WS, et al. 2017 ACC/AHA/ AAPA/ABC/ACPM/AGS/APhA/ASH/ASPC/NMA/PCNA guideline for the prevention, detection, evaluation, and management of high blood pressure in adults: a report of the American College of Cardiology/American Heart Association task force on clinical practice guidelines. J Am Coll Cardiol 2018;71:e127-e248.

16. Other pharmaceutical agents. IARC Monogr Eval Carcinog Risks Hum 2000;76:345-486.

17. Jahan-Tigh RR, Huen AO, Lee GL, Pozadzides JV, Liu P, Duvic M. Hydrochlorothiazide and cutaneous T cell lymphoma: prospective analysis and case series. Cancer 2013;119:825-831.
18. Pottegard A, Hallas J, Olesen M, et al. Hydrochlorothiazide use is strongly associated with risk of lip cancer. J Intern Med 2017;282:322-331.

19. Pedersen SA, Gaist D, Schmidt SAJ, Holmich LR, Friis S, Pottegard A. Hydrochlorothiazide use and risk of nonmelanoma skin cancer: a nationwide case-control study from Denmark. J Am Acad Dermatol 2018;78:673-681.

20. Pedersen SA, Johannesdottir Schmidt SA, Holmich LR, Friis S, Pottegard A, Gaist D. Hydrochlorothiazide use and risk for Merkel cell carcinoma and malignant adnexal skin tumors: a nationwide case-control study. J Am Acad Dermatol 2019;80:460-465.

21. Gandini S, Palli D, Spadola G, et al. Anti-hypertensive drugs and skin cancer risk: a review of the literature and meta-analysis. Crit Rev Oncol Hematol 2018;122:1-9.

22. Kaae J, Boyd HA, Hansen AV, Wulf HC, Wohlfahrt J, Melbye $\mathrm{M}$. Photosensitizing medication use and risk of skin cancer. Cancer Epidemiol Biomarkers Prev 2010;19:29422949.

23. Ruiter R, Visser LE, Eijgelsheim M, et al. High-ceiling diuretics are associated with an increased risk of basal cell carcinoma in a population-based follow-up study. Eur J Cancer 2010;46:2467-2472.

24. Kim L, Kim JA, Kim S. A guide for the utilization of Health Insurance Review and Assessment Service national patient samples. Epidemiol Health 2014;36:e2014008.

25. Friedman GD, Asgari MM, Warton EM, Chan J, Habel LA. Antihypertensive drugs and lip cancer in non-Hispanic whites. Arch Intern Med 2012;172:1246-1251.

26. Jensen AO, Thomsen HF, Engebjerg MC, Olesen AB, Sorensen HT, Karagas MR. Use of photosensitising diuretics and risk of skin cancer: a population-based case-control study. Br J Cancer 2008;99:1522-1528.

27. Robinson SN, Zens MS, Perry AE, Spencer SK, Duell EJ, Karagas MR. Photosensitizing agents and the risk of non-melanoma skin cancer: a population-based case-control study. J Invest Dermatol 2013;133:1950-1955.

28. Schmidt SA, Schmidt M, Mehnert F, Lemeshow S, Sorensen HT. Use of antihypertensive drugs and risk of skin cancer. J Eur Acad Dermatol Venereol 2015;29:15451554 .

29. Tang H, Fu S, Zhai S, Song Y, Han J. Use of antihypertensive drugs and risk of malignant melanoma: a meta-analysis of observational studies. Drug Saf 2018;41:161-169.

30. European Medicines Agency: Pharmacovigilance Risk Assessment Committee (PRAC) 2018; 2018 Oct 29-31; Lon- 
don, UK.

31. van Veelen A, Nielen JTH, van Geel R, Croes S. Response to 'Hydrochlorothiazide use and risk of nonmelanoma skin cancer: a nationwide case-control study from Denmark'. J Am Acad Dermatol 2019.

32. Youn JI, Oh JK, Kim BK, et al. Relationship between skin phototype and MED in Korean, brown skin. Photodermatol Photoimmunol Photomed 1997;13:208-211.

33. Sato K, Dohi Y, Kojima M, Takase H, Suzuki S, Ito S. Antioxidative effects of thiazide diuretics in refractory hypertensive patients. A randomized crossover trial of chlortalidone and trichlormethiazide. Arzneimittelforschung 2010;60:612-616.

34. Kerkela E, Saarialho-Kere U. Matrix metalloproteinases in tumor progression: focus on basal and squamous cell skin cancer. Exp Dermatol 2003;12:109-125.

35. Ceron CS, Castro MM, Rizzi E, et al. Spironolactone and hydrochlorothiazide exert antioxidant effects and reduce vascular matrix metalloproteinase-2 activity and expression in a model of renovascular hypertension. Br J Pharmacol 2010;160:77-87.

36. Nakane H, Kamouchi M, Hata J, et al. Effects of hydrochlorothiazide on oxidative stress and pulse pressure in hypertensive patients with chronic stroke: the EMINENT study. Intern Med 2015;54:573-577.

37. O'Grady A, Dunne C, O'Kelly P, Murphy GM, Leader M, Kay E. Differential expression of matrix metalloproteinase (MMP)-2, MMP-9 and tissue inhibitor of metalloproteinase (TIMP)-1 and TIMP-2 in non-melanoma skin cancer: implications for tumour progression. Histopathology 2007;51:793-804.

38. Lee SG, Yoon HS, Bae H, et al. Implication of ultraviolet $\mathrm{B}$ radiation exposure for non-melanoma skin cancer in Korea. Mol Cell Toxicol 2014;10:91-94. 